\title{
Combination of Artesunate and WNT974 Induces KRAS Protein Degradation by Upregulating E3 Ligase ANACP2 and $\beta$-TrCP in the Ubiquitin- Proteasome Pathway
}

RUIHONG GONG ( $\nabla$ gongruihong@hkbu.edu.hk)

Hong Kong Baptist University https://orcid.org/0000-0002-4555-0394

Minting Chen

Hong Kong Baptist University

Chunhua Huang Huang

Hong Kong Baptist University

Hoi Leong Xavier Wong

Hong Kong Baptist University

Hiu Yee Kwan

Hong Kong Baptist University

Zhaoxiang Bian Bian

Hong Kong Baptist University

\section{Research}

Keywords: Colorectal cancer, KRAS, Artesunate, WNT974, Combination treatment, Protein degradation.

Posted Date: October 1st, 2021

DOl: https://doi.org/10.21203/rs.3.rs-744967/v2

License: (c) (i) This work is licensed under a Creative Commons Attribution 4.0 International License.

Read Full License

Version of Record: A version of this preprint was published at Cell Communication and Signaling on March 19th, 2022. See the published version at https://doi.org/10.1186/s12964-022-00834-2. 


\section{Abstract}

\section{Background}

KRAS mutation is one of the dominant gene mutations in colorectal cancer (CRC). Up to present, targeting KRAS for CRC treatment remains a clinical challenge. WNT974 (LGK974) is a porcupine inhibitor that interferes Wnt signaling pathway. Artesunate (ART) is a water-soluble semi-synthetic derivative of artemisinin.

\section{Methods}

The synergistic effect of ART and WNT974 combination in reducing CRC cell viability was determined by the 3-(4,5-dimethylthiazol-2-yl)-2,5-diphenyltetrazolium bromide (MTT) assay. RT-PCR was utilized for the mRNA levels of KRAS, CUL7, ANAPC2, UBE2M, RNF123, SYVN1, or $\beta$-TrCP. Western blot assay was utilized for the protein levels of KRAS, ANAPC2, $\beta$-TrCP, or GSK-3 $\beta$. Xenograft mouse model assay was performed for the anti-CRC effect of combination of ART and WNT974 in vivo. IHC assay was utilized for the levels of KRAS, $\beta-T r C P$, or GSK-3 $\beta$ in tumor tissues.

\section{Results}

Our study shows that the combination of WNT974 and ART exhibits synergistic effect in reducing CRC growth. The combination treatment significantly reduces KRAS protein level and activity in CRC cells. Interestingly, the combination treatment increases E3 ligases ANAPC2 expression. Our data show that overexpression of ANAPC2 significantly reduces KRAS protein levels, which is reversed by MG132. Knockdown of ANAPC2 in CRC abolishes the combination treatment-reduce KRAS expression. Besides, the treatment also increases the expressions of GSK-3 $\beta$ and E3 ligase $\beta$-TrCP that is known to degrade GSK-3 $\beta$-phosphorylated KRAS protein. Knockdown of $\beta$-TrCP- and inhibition of GSK-3 $\beta$ abolish the combination treatment-induce KRAS ubiquitination and reduction in expression.

\section{Conclusions}

Our data clearly show that the combination treatment significantly enhances KRAS protein degradation via the ubiquitination ubiquitin-proteasome pathway, which is also demonstrated in xenograft mouse model. The study provides strong scientific evidence for the development of the combination of WNT974 and ART as KRAS-targeting therapeutics for CRC treatment.

\section{Background}

Colorectal cancer (CRC) is one of the most common malignant tumors of the gastrointestinal tract. It is a highly heterogeneous disease with diverse genetic background. KRAS (kirsten rat sarcoma viral oncogene) mutation is one of the dominant mutations in CRC, which accounts for $40 \%$ of all the CRC cases [1]. The most common KRAS mutations are at codon 12 and 13 , followed by mutations at codons 61 and 146 [2]. 
KRAS is downstream of epidermal growth factor receptor (EGFR). Upon EGFR activation, the tyrosine kinase in the intracellular region phosphorylates and activates KRAS and hence activates the RAS-RAFMAPK signaling pathway. The activated KRAS-GTP will then be hydrolyzed by GTPase and switches back to the inactivate KRAS-GDP state. Therefore, KRAS is switched between the active (KRAS-GTP) and inactive (KRAS-GDP) states. However, mutations in KRAS result in aberrant activation of the downstream RAS-RAF-MAPK or phosphoinositide 3-kinase pathways, regardless of the EGFR activation status [3, 4].

Since KRAS activity is regulated by farnesylation-mediated protein modifications [5], farnesyl transferase inhibitors have been developed. Although they were effective in preclinical models, they failed in the clinical studies [6, 7]. Therapeutic approaches also include targeting KRAS downstream signaling with kinase inhibitors for the rapidly accelerated fibrosarcoma, mitogen-activated protein kinase kinase and extracellular signal-regulated kinase. However, only a minority of these provides marginal survival advantages to the CRC patients carrying KRAS mutations; moreover, the treatments result in significant adverse events [8]. Furthermore, CRC patients harboring KRAS mutations are insensitive to the current anti-EGFR therapy [9], which further limits their treatment choices.

Up to present, no effective pharmacological inhibitors for the KRAS oncoproteins has been approved for cancer treatment, leading to the perception that KRAS proteins are 'undruggable'. Indeed, based on the structure and regulatory mechanisms of the KRAS, researchers have identified a number of challenges in targeting KRAS for disease treatments such as lack of binding sites on the KRAS protein surface for the binding of small molecule inhibitors [10-12]. Nevertheless, interrupting the KRAS-membrane interaction and disrupting the KRAS subcellular localization remain as attractive therapeutic strategies. Recent studies on the functionally relevant post-translational modifications of KRAS protein such as phosphorylation and ubiquitylation also suggest new opportunities to inhibit KRAS activity.

WNT974 (also known as LGK974) is a selective and orally bioavailable (PORCN) inhibitor. PORCN is a membrane-bound 0-acyltransferase in the endoplasmic reticulum that adds the palmitoyl group to Wnt ligands, which is a necessary step for processing Wnt ligand secretion [13]. WNT974 inhibits PORCN and hence the secretion of Wnt ligands and interferes the Wnt-mediated signaling. WNT974 is developed to treat Wnt-driven cancers [14]. It shows significant effects in several cancer types including ovarian cancer [15], lung cancer [16], squamous cell carcinoma [17, 18], glioblastoma [19, 20] and colon cancer [21]. Indeed, WNT974 is in clinical trial phase I and phase II (NCT01351103, NCT02278133) for CRC treatment $[22,23]$.

Many bioactive compounds are identified from medicinal herbs [24]. Artemisia annua L. is a medicinal plant used to treat fever and chills. Artemisinin, is an bioactive compound isolated from Artemisia annua L. Artesunate (ART) is a water-soluble semi-synthetic derivative of artemisinin, which is approved for treating severe malaria cases [25]. ART is also known to specifically inhibits cancer cell growth but not the normal cells [26-29]. National Cancer Institute has also conducted a study and found that several cancer cells including CRC are sensitive to ART treatments. ART is now under clinical trials for treating patients with high-grade anal intraepithelial neoplasia and solid tumour [30]. 
In our study, we found that the combination of WNT974 and ART exhibited synergistic effect in reducing CRC growth. Interestingly, the combination treatment significantly enhanced KRAS protein degradation that may underlie the synergistic effect of the combination treatment.

\section{Methods}

\section{Reagents}

Artesunate (ART) was provided from Kuming Pharmaceutical Co. Ltd. WNT974 was purchased from MedChemExpress company, Dulbecco's Modified Eagle's Medium, fetal bovine serum were purchased

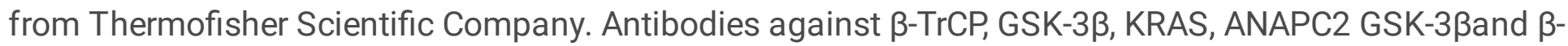
Actin were purchased form Cell Signaling Technology (Danvers, MA). Mouse anti-rabbit IgG-HRP secondary antibody was purchased from San Cruz Biotechnology (Santa Cruz, United States of America).

\section{Cell lines and culture}

HCT116, HT29, SW480, SW620, COLO325, COLO205, HCT15 and RKO cells were purchased from American Type Culture Collection (Manassas, USA). Cells were cultured in DMEM supplemented with 10\% FBS in a humidified atmosphere containing $5 \% \mathrm{CO}_{2}$ and $95 \%$ air at $37^{\circ} \mathrm{C}$. The medium was changed every three days, and cells were passaged using $0.05 \%$ trypsin/EDTA.

\section{Western blot analysis}

Proteins were extracted from CRC cells with RIPA lysis buffer, followed by centrifugation at 13,500 rpm for $15 \mathrm{~min}$ at $4^{\circ} \mathrm{C}$. Protein concentration was measured using Pierce (R) BCA Protein Assay Kit, and equal amount of protein was separated on 10\% SDS-PAGE and transferred to PVDF membranes. After blocking ( $5 \%$ skim milk powder in TBST, 20) for $1 \mathrm{~h}$ at room temperature, the membrane was then incubated with the respective primary antibody overnight at $4^{\circ} \mathrm{C}$. Afterward, the membrane was incubated with secondary antibody for $1 \mathrm{~h}$ at room temperature. All antibodies were diluted in TBS-Tween 20 containing $5 \%$ dry milk. The immune-reactive proteins were detected by enhanced chemiluminescence $(E C L)$ using X-ray film and ECL reagent.

\section{KRAS activity}

The ubiquitinated proteins were isolated using the UBIQAPTURE-Q® kit (UW8995, Enzo Life Sciences). KRAS protein activity was examined by the KRAS activation assay kit (ab211159, Abcam) following company's instruction.

\section{Real time PCR analysis}

RNA was extracted from CRC cells using TRIzol reagent (Invitrogen), and cDNAs were subsequently prepared by reverse transcription. RT Profiler PCR Array experiment was performed following the instruction of RT2 Profiler PCR Array kit (QIAGEN). Quantitative polymerase chain reaction (PCR) was performed using the Quantitect SYBR Green PCR Master Mix (Qiagen, Valencia, CA) with $1 \mu \mathrm{L}$ cDNA in a 
final volume of $10 \mu \mathrm{L}$ and the following primers at a final concentration of $1000 \mathrm{nM}$. Primers for ANAPC2 were 5'-GGCAGCAAGGACCTCTTCAT-3' (forward) and 5'-CTTGCTCAGTTCCTCCAGGG-3' (reverse). Primers for CUL7 were 5'-GTGGCATTGATACGCGCATT-3' (forward) and 5'- CTCCAGTCGTGGCTTCTGTT - 3' (reverse). Primers for UBE2M were 5'-GCAGCAGAAGAAGGAGGAGG-3' (forward) and 5'GTAGGTGGAGCCGATGTAGC-3' (reverse). Primers for RNF123 were 5'-ATCCAGGGTCACAGGCATTG-3' (forward) and 5'-CCACGCCTTGCCATAATTCG-3' (reverse). Primers for SYVN1 were 5'CTGCCTCCTTTTCCTCCAGG-3' (forward) and 5'-TCTGAGCTAGGGATGCTGGT-3' (reverse). Primers for NEDD4 were 5'- AGCCAGAGTTCTGCAGGCCCT-3' (forward) and 5'- GCTGGGAAGTCCGGCATGCA-3' (reverse). Primers for $\beta$-Trcp were 5'- AAGCGAATTCTCACAGGCCA - 3' (forward) and 5'TCCATCATAGGCCCCACTGA - 3' (reverse). Primers for PEAK were 5'- ACCAGTCTCGCCTTGCCCCA - 3' (forward) and 5'- GGGGAGCGGAATGGGATGCG - 3' (reverse). Primers for elF5A were 5'CCTGGTGGGGGAGAAGGGGG-3' (forward) and 5'-CCTGAGGAGGGGGCAGGTCC-3' (reverse). Primers for RAK were 5'- TCCCAGCTCCATTTGATTTGTC-3' (forward) and 5'- TGACCAGATCCCAATCGCTTC-3' (reverse). Primers for SMURF-2 were 5'- GTGGTTGATGGATCTGGGCA-3' (forward) and 5'ACTGTCCACATGTTGCACCA-3' (reverse). Primers for UBCH5 were 5'- AGCGCATATCAAGGTGGAGT-3' (forward) and 5'- AGCTGAAGATGCAGATGTCCA - 3' (reverse). Amplification of the cDNAs was performed using the LightCycler 2000 instrument (Roche, Indianapolis, IN). The cycling conditions comprised a denaturation step for 15 minutes at $95^{\circ} \mathrm{C}$, followed by 40 cycles of denaturation ( $95^{\circ} \mathrm{C}$ for 15 seconds), annealing $\left(59^{\circ} \mathrm{C}\right.$ for 20 seconds), and extension $\left(72^{\circ} \mathrm{C}\right.$ for 15 seconds). After amplification, a melting curve analysis was performed with denaturation at $95^{\circ} \mathrm{C}$ for 5 seconds, then continuous fluorescence measurement was made from $70^{\circ} \mathrm{C}$ to $95^{\circ} \mathrm{C}$ at $0.1^{\circ} \mathrm{C} /$ second. Each sample was amplified in duplicate.

\section{siRNA transfection}

HCT116 cells or SW620 cells were seeded in 6-well plates. p21 or p27 siRNA were diluted to $10 \mu \mathrm{M}$ working concentration for transfection. Then, $5 \mu \mathrm{L}$ Lipofectamine ${ }^{\circledR}$ RNAiMax transfection reagent (Invitrogen) was added to $150 \mu \mathrm{L}$ medium without serum in one tube, and $3 \mu \mathrm{L}$ of prepared siRNA was added to $150 \mu \mathrm{L}$ medium without serum, and incubated for 20 mins at room temperature before adding to the well and cultured for $24 \mathrm{~h}$.

\section{CRC-bearing xenograft mouse model}

The six-week-old male BALB/c nude mice were housed in the Laboratory Animal House of Hong Kong Baptist University. The animal house is temperature-controlled with a $12 \mathrm{~h} \mathrm{light/dark} \mathrm{cycle.} \mathrm{Food} \mathrm{and}$ water were available ad libitum. Mice were adapted to the environment for one week before the study. The procedures of all in vivo studies have granted ethics approval by the Animal Experimentation Ethics Committee of the Hong Kong Baptist University. The mice were subcutaneously inoculated with $1 \times 10^{6}$ HCT116 cells in the left armpit. Once tumors were palpable $\left(\sim 100 \mathrm{~mm}^{3}\right)$, the tumor-bearing nude mice were randomly divided into groups with five mice in each group for further studies. (1) Vehicle group (daily i.p. saline), (2) ART group (daily i.p. $30 \mathrm{mg} / \mathrm{kg}$ of artesunate), (3) WNT974 group (daily i.p. $5 \mathrm{mg} / \mathrm{kg}$ of WNT974), (4) ART combined with WNT974 group (daily i.p. $30 \mathrm{mg} / \mathrm{kg}$ artesunate and $5 \mathrm{mg} / \mathrm{kg}$ 
WNT974), (5) 5-Fu group (daily i.p. $10 \mathrm{mg} / \mathrm{kg}$ of 5-Fu). The tumor size and body weight were monitored every day.

\section{Immunohistochemical staining}

Paraffin sections of tumors were deparaffinized using xylene and then rehydrated by immersing in alcohol at series of concentrations. Endogenous peroxidase was quenched by 10 min incubation with $3 \%$ hydrogen peroxide. Blocking serum of 1:10 was used for blocking the non-specific bindings of epitopes. The sections were incubated with $\beta$-TrCP, GSK-3 $\beta$ and KRAS antibody of $1: 100$ at $4^{\circ} \mathrm{C}$ overnight. Slides were then washed three times, incubated with a biotinylated secondary antibody (Santa Cruz) for 30 min, and then with peroxidase substrate for $10 \mathrm{~min}$. The sections were finally washed, incubated in deionized water for $5 \mathrm{~min}$, counterstained with hematoxylin before analyzing by microscopy (NIKON Eclipse ci, NIKON digital sight DS-FI2, Japan).

\section{Statistical analysis}

The data were shown as mean \pm standard errors with three independent experiments. Statistical analysis

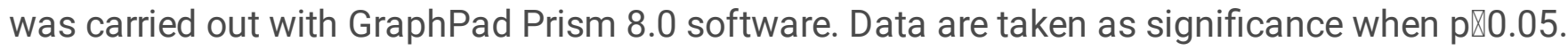

\section{Results}

The combination of WNT974 and artesunate (ART) reduces KRAS protein level and activity in CRC cells

The combination of WNT974 and ART exhibited synergistic effect in reducing CRC cell viability (Fig. 1A) as indicated by the combination index $(\mathrm{Cl})<1$. Interestingly, the combination of WNT974 and ART significantly reduced KRAS protein levels (Fig. 1B) in the CRC cells when compared to WNT974 or ART mono-treatments. The treatment did not affect the KRAS mRNA levels (Fig. 1C). We also examined the KRAS activity in these cells by using Raf1 RBD agarose beads to selectively pull-down the active form of KRAS from the protein samples. Figure 1B showed that the combination treatment significantly reduced KRAS activity in the CRC cells when compared to control or the monotreatments. These results imply that the reduced KRAS protein expression and activity may be associated with the synergistic effect of the combination treatment in reducing CRC growth.

\section{The combination of WNT974 and ART induces KRAS protein degradation in CRC cells}

Post-translational modifications of KRAS protein such as ubiquitylation and degradation may reduce the protein expression [31]. The ubiquitin proteasome pathway consists of concerted actions of enzymes that link chains of the polypeptide co-factor, ubiquitin, onto proteins to mark them for degradation [32]. We next examined whether the combination treatment affected KRAS ubiquitination. As shown in Fig. 2A, the combination treatment markedly enhanced KARS ubiquitination in the CRC cells when compared to the mono-treatments. To further examine whether the treatment affected KRAS protein degradation, we treated the cells with WNT974, ART or the combination of both in presence or absence of MG132. MG132 
is a specific, potent, reversible cell-permeable proteasome inhibitor [33]. As shown in Fig. 2B and 2C, MG132 abolished the combination treatment-reduced KRAS protein expression, suggesting the combination of WNT974 and ART induces KRAS degradation via the ubiquitination proteasome pathway.

\section{The combination of WNT974 and ART induces KRAS protein degradation by increasing anaphase promoting complex subunit 2 (ANAPC2) expression}

Next, we examined how the combination treatment induced KRAS degradation in CRC cells. Firstly, we used PCR array for the human ubiquitination pathway (genes layout in Table 1) to examine whether the treatments affected the expressions of the genes that are involved in the ubiquitination pathway. As shown in Fig. 3A, the heat map indicated that the treatments affected the gene expressions, the numbers of up- or down-regulated genes were shown in Fig. 3B. The results showed that, compared to control, ART treatment upregulated 15 genes and downregulated 34 genes; WNT974 treatment upregulated 13 genes and downregulated 20 genes; and the combination treatment upregulated 18 genes and downregulated 27 genes. Compared to ART treatment, the combination treatment upregulated 12 genes and downregulated 9 genes. Compared to WNT974 treatment, the combination treatment upregulated 12 genes and downregulated 10 genes. More importantly, we found that 5 genes were upregulated by more than 2-fold under the combination treatment when compared to the mono-treatments. These ubiquitination related genes were CUL7 (cullin), ANAPC2, UBE2M (ubiquitin conjugating enzyme E2M), SYVN1 (synoviolin 1) and RNF123 (RING finger protein123) (Fig. 3C),

To examine whether these gene candidates were involved in the combination treatment reduced KRAS protein expression, we used siRNA to mediate the knockdown of the gene candidates before the treatments. The upper panels in Figs. 3D to 3H showed the siRNA-mediated knockdown of the candidates (CUL7, ANAPC2, UBE2M, SYVN1, RNF123) in the CRC cells. We found that the combination treatment could significantly reduce KRAS protein level in the CUL7-, UBE2M-, SYVN1-, RNF123-knockdown cells (Fig. 3D, 3F to 3H). However, the combination treatment failed to reduce KRAS protein level in the ANAPC2-knockout cells (Fig. 3E), implying ANAPC2 was involved in the combination treatment-reduced KRAS protein expression.

We further validated the role of ANAPC2 in KRAS protein degradation. We found that ANAPC2 overexpression (Fig. 3I) significantly reduced KRAS protein levels (Fig. 3J), which was reversed in the presence of MG132 (Fig. 3J). Furthermore, we also found that the combination treatment significantly increased ANAPC2 protein expression when compared to the mono-treatments (Fig. 3K). Our data strongly suggest that the combination treatment increases ANAPC2 expression and hence increases KRAS protein degradation in the CRC cells.

The combination of WNT974 and ART induces KRAS protein degradation by increasing $\beta$-TrCP and GSK$3 \beta$ expressions

We further explored whether other gene candidates would affect KRAS expressions and degradation under the combination treatment. Other studies have reported that elF5A and PEAK increased KRAS 
protein synthesis; NEDD4 and $\beta$-TrCP which are E3 ligase will promote KRAS degradation; SMURF2 and UBCH5 as a critical E3:E2 complex maintaining KRAS protein stability [34-36]. In our study, we found that combination treatment did not significantly affect the mRNA expressions of elF5A, NEDD4, PEAK, SMURF2, UBCH5 (Supplementary Figure S1A to S1J), but significant increased $\beta$-TrCP mRNA level (Fig. 4A and 4B) and protein level (Fig. 4C) in the CRC cells. $\beta$-TrCP is an F-box ubiquitin ligase, it has been implicated in RAS (including KRAS) ubiquitination and degradation [35, 37, 38]. $\beta$-TrCP degrades KRAS protein and in this degradation process, glycogen synthase kinase-3 beta (GSK-3 $\beta$ ) mediates the phosphorylation of KRAS for the priming of $\beta$-TrCP to the KRAS protein for degradation [35]. Interestingly, the combination treatment not only increased $\beta$-TrCP expression but also GSK-3 $\beta$ expression (Fig. 4D).

We then examined whether $\beta$-TrCP would affect the KRAS protein expression in the CRC cells.

We used siRNA to mediate the knockdown of $\beta$-TrCP in the CRC cells (Fig. 4E to 4H). We found that in the $\beta$-TrCP-knockdown cells, KRAS protein expression was increased (Fig. $4 \mathrm{I}$ and $4 \mathrm{~J}$ ). More importantly, in these cells, in the presence of GSK-3 $\beta$ inhibitor, the combination treatment failed to induce KRAS ubiquitination (Fig. 4K) and reduce KRAS protein expression (Fig. 4L). Taken together, the data strongly suggest that the combination treatment increases $\beta-\operatorname{TrCP}$ and GSK-3 $\beta$ expressions that lead to the KRAS degradation in CRC.

\section{The combination of WNT974 and ART exhibits a potent anti-CRC effect in vivo}

Next, we examined the anti-CRC effect of the treatments with CRC-bearing xenograft mouse model. After 12-days of treatment, the combination treatment significantly reduces the tumor size (Fig. 5A and 5B) and the percentage increase in tumor size (Fig. $5 \mathrm{C}$ ) when compared to the control and monotreatments. The combination treatment did not significantly affect the body weight of the mice (Fig. 5D), suggesting the treatments do not have apparent toxicity to the mice. In parallel with the in vitro data, the combination treatment significantly increased $\beta$-TrCP and GSK-3 $\beta$ expressions and reduced KRAS expression levels in the tumor tissues of these mice (Fig. 5E and 5F).

\section{Discussion}

Our study shows that the combination of WNT974 and ART significantly inhibits CRC growth. Mechanistic studies suggest that the combination treatment reduces KRAS protein expressions by inducing KRAS protein degradation via the ubiquitination pathway, which may attribute to the elevated expressions of ANACP-2, beta-TrCP and GSK-3ß (Fig. 6).

The development of CRC is associated with the abnormal function of cellular transmembrane signaling systems [39]. KRAS is a well-known oncogene in CRC. It is susceptible to mutations. The most common KRAS gene mutation is at glycine at G12, G13 and glutamine at Q61, while G12 has 15 different point mutations. These mutation leads to the aberrant activation of the signaling pathways including the RAF/MEK/MAPK pathway, PI3K/AKT pathway and RAGDS, RAL-RLIP pathways, leading to the malignant CRC progression and development $[40,41]$. Furthermore, KRAS mutation also influences the choice of 
surgical techniques and is an independent predictor for positive resection margins $(\mathrm{HR} 2.44,95 \%, \mathrm{Cl}$ $1.30-4.58, P=0.005)[42]$.

Direct targeting KRAS mutant has been suggested as a therapeutic strategy. $\mathrm{SCH}-53239$ was the first KRAS inhibitor that was designed to compete with GDP for the nucleotide binding site on the KRAS protein [43]. However, the efficacy was impeded by the fact that the hydrophobic pockets on the KRAS protein surface is not well-defined. Besides, the compound was toxic, and has not been approved by the Food and Drug Administration (FDA) for cancer treatment [44, 45]. Up to present, targeting KRAS for CRC treatment remains a clinical challenge [44]. Our data clearly show that the combination treatment significantly reduces CRC cell viability in eight different CRC cell lines and reduces KRAS expression and activity. These cells harbor different gene mutations including KRAS mutations in HCT116 and SW620 cells. Therefore, our data suggest that the combination treatment can be developed as KRAS-targeting therapeutics for treating $\mathrm{CRC}$ regardless of the mutation statuses.

Ubiquitination is an important protein posttranslational modification (PTM), it plays a crucial role in controlling protein degradation and maintaining a homeostasis [46]. Tumorigenesis involves many altered biological processes. Ubiquitination of some key signaling proteins such as RagA [47, 48], mTOR [49], PTEN [50, 51], AKT [52, 53], c-Myc [54, 55] and P53 [56, 57] have implicated in the tumor growth. Therefore, targeted ubiquitination and degradation of oncoproteins via the ubiquitin-proteasome pathway represents an alternative therapeutic strategy. By targeting the proteasome, E3 ligases, E1, E2 and deubiquitinases (DUBs), many targeted compounds have been developed to combat cancer, such as bortezomib, carfilzomib, oprozomib and ixazomib [58]. One of the most important components of the ubquitin conjugation machinery is E3 ligases that mediate protein degradation with high substrate specificity. Thus, targeting the active site of E3 enzymes or their interactions with substrates offers promising options for developing drugs with reduced side effects [59]. For example, Nedd4-1 is a general E3 ubiquitin ligase that controls the abundance of Ras. The interplay between Ras-regulated transcription of Nedd4-1 and Nedd4-1-mediated Ras degradation comprises a negative feedback regulatory loop [34]. Recently, it is found that KRAS is targeted for polyubiquitylation by E3 ligase $\beta$-TrCP and then subsequently degraded by the proteasomal degradation machinery [35, 37]. Our data show that the combination of WNT974 and ART increases $\beta$-TrCP expressions and hence KRAS protein degradation. Our study also, for the first time, revealing the regulatory role of E3 ligase ANAPC2 on KRAS protein degradation. ANAPC2 may be another therapeutic target that can increase KRAS protein degradation in CRC.

\section{Conclusions}

In conclusion, we report a novel discovery for the combination of WNT974 and ART in inducing KRAS protein degradation in CRC. The combination treatment significantly increases the levels of E3 ligase ANAPC2 and $\beta$-TrCP and the expression of GSK-3 $\beta$, which lead to KRAS protein degradation via the ubiquitination ubiquitin-proteasome pathway. This study provides strong scientific evidence for the development of the combination of WNT974 and ART as KRAS-targeting therapeutics for CRC treatment. 


\section{Abbreviations}

CRC

colorectal cancer

ART

artesunate

MTT

3-(4,5-dimethylthiazol-2-yl)-2,5-diphenyltetrazolium bromide

\section{RT-PCR}

real-time polymerase chain reaction

IHC

immunohistochemistry

KRAS

kirsten rat sarcoma viral oncogene

GDP

guanosine diphosphate

GTP

Guanosine triphosphate

EGFR

epidermal growth factor receptor

PORCN

porcupine

DMEM

Dulbecco's modified Eagle's medium

FBS

Fetal bovine serum

PBS

Phosphate-buffered saline

CDNA

Complementary DNA

CUL7

cullin

ANAPC2

anaphase promoting complex subunit 2

\section{UBE2M}

ubiquitin conjugating enzyme E2M

SYVN1

synoviolin 1

RNF123

RING finger protein 123 
elF5A

Eukaryotic translation initiation factor $5 \mathrm{~A}$

NEDD4

Neuronal precursor cell-expressed developmentally down-regulated 4

PEAK

pseudopodium enriched atypical kinase

SMURF2

SMAD Specific E3 Ubiquitin Protein Ligase 2

UBCH5

ubiquitin Conjugating Enzyme E2 D1

\section{Declarations}

\section{Ethical Approval}

The procedures of all animal studies have granted ethics approval by the Animal Experimentation Ethics Committee of the Hong Kong Baptist University.

\section{Consent for publication}

Not applicable.

\section{Availability of supporting data}

The datasets used and/or analysed during the current study are available from the corresponding author on reasonable request.

\section{Competing interests}

The authors declare that they have no competing interests.

\section{Funding}

This work was partially supported by Research Grant Council of HKSAR (\#HKBU-22103017-ECS), Innovation \& Technology Commission (\#PRP/015/19FX), Natural Science Foundation of Guangdong Province (\#2018A0303130122, \#2021A1515010655), Health and Medical Research Fund (\#08193596), HKBU FNRA-IG (\#RC-FNRA-IG/20-21/SCM/01) to HYK; National Natural Science Foundation of China (\#81973538)هHealth and Medical Research Fund (\#7182661), Key-Area Research and Development Program of Guangdong Province (\#2020B1111110003) and Professor Martha Cheung Chinese Medicine Research Fund to BX.

\section{Authors' contributions}


Conceptualization: RHG, HYK, ZB. Data curation and formal analysis: RHG, MTC, CHH. Writing: RHG, HYK. Review and editing: HLXW, HYK, ZB. All authors read and approved the final manuscript.

\section{Acknowledgements}

Not applicable.

\section{Authors' information}

\section{Affiliations}

Centre for Cancer and Inflammation Research, School of Chinese Medicine, Hong Kong Baptist University, Hong Kong, China.

Rui-Hong Gong, Minting Chen, Chunhua Huang, Hoi Leong Xavier Wong, Hiu Yee Kwan, Zhaoxiang Bian

\section{Corresponding authors}

Correspondence to Hiu Yee Kwan or Zhaoxiang Bian.

\section{References}

1. Yu SH, Wang TH, Au LC. Specific repression of mutant K-RAS by 10-23 DNAzyme: sensitizing cancer cell to anti-cancer therapies. Biochem Biophys Res Commun. 2009 Jan 9;378(2):230-4. doi: 10.1016/j.bbrc.2008.11.027.

2. Tan C, Du X. KRAS mutation testing in metastatic colorectal cancer. World J Gastroenterol. 2012 Oct 7;18(37):5171-80. doi: 10.3748/wjg.v18.i37.5171.

3. Yokota T. Are KRAS/BRAF mutations potent prognostic and/or predictive biomarkers in colorectal cancers? Anticancer Agents Med Chem. 2012 Feb;12(2):163-71. doi:10.2174/187152012799014968.

4. Domagała P, Hybiak J, Sulżyc-Bielicka V, Cybulski C, Ryś J, Domagała W. KRAS mutation testing in colorectal cancer as an example of the pathologist's role in personalized targeted therapy: a practical approach. Pol J Pathol. 2012 Nov;63(3):145-64. doi:10.5114/pjp.2012.31499.

5. Prior IA, Hancock JF. Ras trafficking, localization and compartmentalized signalling. Semin Cell Dev Biol. 2012 Apr;23(2):145-53. doi:10.1016/j.semcdb.2011.09.002.

6. Quinlan MP, Settleman J. Isoform-specific ras functions in development and cancer. Future Oncol. 2009 Feb;5(1):105-16. doi:10.2217/14796694.5.1.105.

7. Eisenberg S, Henis YI. Interactions of Ras proteins with the plasma membrane and their roles in signaling. Cell Signal. 2008 Jan;20(1):31-9. doi: 10.1016/j.cellsig.2007.07.012.

8. Lakatos G, Köhne CH, Bodoky G. Current therapy of advanced colorectal cancer according to RAS/RAF mutational status. Cancer Metastasis Rev. 2020 Dec;39(4):1143-57. doi:10.1007/s10555020-09913-7. 
9. Misale S, Yaeger R, Hobor S, Scala E, Janakiraman M, Liska D, Valtorta E, Schiavo R, Buscarino M, Siravegna G, Bencardino K, Cercek A, Chen CT, Veronese S, Zanon C, Sartore-Bianchi A, Gambacorta M, Gallicchio M, Vakiani E, Boscaro V, Medico E, Weiser M, Siena S, Di Nicolantonio F, Solit D, Bardelli A. Emergence of KRAS mutations and acquired resistance to anti-EGFR therapy in colorectal cancer. Nature. 2012 Jun 28;486(7404):532-6. doi: 10.1038/nature11156.

10. Cox AD, Fesik SW, Kimmelman AC, Luo J, Der CJ. Drugging the undruggable RAS: Mission possible? Nat Rev Drug Discov. 2014 Nov;13(11):828-51. doi:10.1038/nrd4389.

11. Ledford H. Cancer. The Ras renaissance. Nature. 2015 Apr 16;520(7547):278 - 80. doi: 10.1038/520278a.

12. Lu S, Jang H, Gu S, Zhang J, Nussinov R. Drugging Ras GTPase: a comprehensive mechanistic and signaling structural view. Chem Soc Rev. 2016 Sep 21;45(18):4929-52. doi: 10.1039/c5cs00911a.

13. Ho SY, Keller TH. The use of porcupine inhibitors to target Wnt-driven cancers. Bioorg Med Chem Lett. 2015 Dec 1;25(23):5472-6. doi: 10.1016/j.bmcl.2015.10.032.

14. Liu J, Pan S, Hsieh MH, Ng N, Sun F, Wang T, Kasibhatla S, Schuller AG, Li AG, Cheng D, Li J, Tompkins C, Pferdekamper A, Steffy A, Cheng J, Kowal C, Phung V, Guo G, Wang Y, Graham MP, Flynn S, Brenner JC, Li C, Villarroel MC, Schultz PG, Wu X, McNamara P, Sellers WR, Petruzzelli L, Boral AL, Seidel HM, McLaughlin ME, Che J, Carey TE, Vanasse G, Harris JL. Targeting Wnt-driven cancer through the inhibition of Porcupine by LGK974. Proc Natl Acad Sci U S A. 2013 Dec;10(50):20224-9. doi:10.1073/pnas.1314239110.110) .

15. Boone JD, Arend RC, Johnston BE, Cooper SJ, Gilchrist SA, Oelschlager DK, Grizzle WE, McGwin G Jr, Gangrade A, Straughn JM Jr, Buchsbaum DJ. Targeting the Wnt/ $\beta$-catenin pathway in primary ovarian cancer with the porcupine inhibitor WNT974. Lab Invest. 2016 Feb;96(2):249-59. doi:10.1038/labinvest.2015.150.

16. Guimaraes PPG, Tan M, Tammela T, Wu K, Chung A, Oberli M, Wang K, Spektor R, Riley RS, Viana CTR, Jacks T, Langer R, Mitchell MJ. Potent in vivo lung cancer Wnt signaling inhibition via cyclodextrin-LGK974 inclusion complexes. J Control Release. 2018 Nov 28;290:75-87. doi: 10.1016/j.jconrel.2018.09.025.

17. Zimmerli D, Cecconi V, Valenta T, Hausmann G, Cantù C, Restivo G, Hafner J, Basler K, van den Broek M. WNT ligands control initiation and progression of human papillomavirus-driven squamous cell carcinoma. Oncogene. 2018 Jul;37(27):3753-3762. doi: 10.1038/s41388-018-0244-x.

18. Li H, Jiao S, Li X, Banu H, Hamal S, Wang X. Therapeutic effects of antibiotic drug tigecycline against cervical squamous cell carcinoma by inhibiting Wnt/ $\beta$-catenin signaling. Biochem Biophys Res Commun. 2015 Nov 6;467(1):14-20. doi: 10.1016/j.bbrc.2015.09.140.

19. Kahlert UD, Suwala AK, Koch K, Natsumeda M, Orr BA, Hayashi M, Maciaczyk J, Eberhart CG. Pharmacologic Wnt Inhibition Reduces Proliferation, Survival, and Clonogenicity of Glioblastoma Cells. J Neuropathol Exp Neurol. 2015 Sep;74(9):889-900. doi:10.1097/NEN.0000000000000227.

20. Suwala AK, Koch K, Rios DH, Aretz P, Uhlmann C, Ogorek I, Felsberg J, Reifenberger G, Köhrer K, Deenen R, Steiger HJ, Kahlert UD, Maciaczyk J. Inhibition of Wnt/beta-catenin signaling 
downregulates expression of aldehyde dehydrogenase isoform 3A1 (ALDH3A1) to reduce resistance against temozolomide in glioblastoma in vitro. Oncotarget. 2018 Apr 27;9(32):22703-22716. doi: 10.18632/oncotarget.25210.

21. Picco G, Petti C, Centonze A, Torchiaro E, Crisafulli G, Novara L, Acquaviva A, Bardelli A, Medico E. Loss of AXIN1 drives acquired resistance to WNT pathway blockade in colorectal cancer cells carrying RSPO3 fusions. EMBO Mol Med. 2017 Mar;9(3):293-303. doi:10.15252/emmm.201606773.

22. Pai SG, Carneiro BA, Mota JM, Costa R, Leite CA, Barroso-Sousa R, Kaplan JB, Chae YK, Giles FJ. Wnt/beta-catenin pathway: modulating anticancer immune response. J Hematol Oncol. 2017 May 5;10(1):101. doi: 10.1186/s13045-017-0471-6.

23. Jung YS, Park JI. Wnt signaling in cancer: therapeutic targeting of Wnt signaling beyond $\beta$-catenin and the destruction complex. Exp Mol Med. 2020 Feb;52(2):183-91. doi:10.1038/s12276-020-03806.

24. Tan W, Lu J, Huang M, Li Y, Chen M, Wu G, Gong J, Zhong Z, Xu Z, Dang Y, Guo J, Chen X, Wang Y. Anti-cancer natural products isolated from chinese medicinal herbs. Chin Med. 2011 Jul 22;6(1):27. doi: 10.1186/1749-8546-6-27.

25. Weathers PJ, Towler M, Hassanali A, Lutgen P, Engeu PO. Dried-leaf Artemisia annua: A practical malaria therapeutic for developing countries? World J Pharmacol. 2014 Dec 9;3(4):39-55. doi: 10.5497/wjp.v3.i4.39.

26. Efferth T, Sauerbrey A, Olbrich A, Gebhart E, Rauch P, Weber HO, Hengstler JG, Halatsch ME, Volm M, Tew KD, Ross DD, Funk JO. Molecular modes of action of artesunate in tumor cell lines. Mol Pharmacol. 2003 Aug;64(2):382-94. doi:10.1124/mol.64.2.382.

27. Zhou HJ, Wang WQ, Wu GD, Lee J, Li A. Artesunate inhibits angiogenesis and downregulates vascular endothelial growth factor expression in chronic myeloid leukemia K562 cells. Vascul Pharmacol. 2007 Aug-Sep;47(2-3):131-8. doi: 10.1016/j.vph.2007.05.002.

28. Hou J, Wang D, Zhang R, Wang H. Experimental therapy of hepatoma with artemisinin and its derivatives: in vitro and in vivo activity, chemosensitization, and mechanisms of action. Clin Cancer Res. 2008 Sep 1;14(17):5519-30. doi: 10.1158/1078-0432.CCR-08-0197.

29. Mercer AE, Maggs JL, Sun XM, Cohen GM, Chadwick J, O'Neill PM, Park BK. Evidence for the involvement of carbon-centered radicals in the induction of apoptotic cell death by artemisinin compounds. J Biol Chem. 2007 Mar 30;282(13):9372-9382. doi: 10.1074/jbc.M610375200.

30. National Cancer Institute. https://www.cancer.gov/about-cancer/treatment/clinicaltrials/intervention/artesunat.

31. Burslem GM, Smith BE, Lai AC, Jaime-Figueroa S, McQuaid DC, Bondeson DP, Toure M, Dong H, Qian Y, Wang J, Crew AP, Hines J, Crews CM. The Advantages of Targeted Protein Degradation Over Inhibition: An RTK Case Study. Cell Chem Biol. 2018 Jan 18;25(1):67-77.e3. doi:

10.1016/j.chembiol.2017.09.009.

32. Glickman $\mathrm{MH}$, Ciechanover A. The ubiquitin-proteasome proteolytic pathway: destruction for the sake of construction. Physiol Rev. 2002 Apr;82(2):373-428. doi:10.1152/physrev.00027.2001. 
33. Lee DH, Goldberg AL. Proteasome inhibitors: valuable new tools for cell biologists. Trends Cell Biol. 1998 Oct;8(10):397-403. doi:10.1016/s0962-8924(98)01346-4.

34. Zeng T, Wang Q, Fu J, Lin Q, Bi J, Ding W, Qiao Y, Zhang S, Zhao W, Lin H, Wang M, Lu B, Deng X, Zhou D, Yin Z, Wang HR. Impeded Nedd4-1-mediated Ras degradation underlies Ras-driven tumorigenesis. Cell Rep. 2014 May 8;7(3):871 - 82. doi: 10.1016/j.celrep.2014.03.045.

35. Shukla S, Allam US, Ahsan A, Chen G, Krishnamurthy PM, Marsh K, Rumschlag M, Shankar S, Whitehead C, Schipper M, Basrur V, Southworth DR, Chinnaiyan AM, Rehemtulla A, Beer DG, Lawrence TS, Nyati MK, Ray D. KRAS protein stability is regulated through SMURF2: UBCH5 complex-mediated $\beta$-TrCP1 degradation. Neoplasia. 2014 Feb;16(2):115-28. doi:10.1593/neo.14184.

36. Fujimura K, Wang H, Watson F, Klemke RL. KRAS Oncoprotein Expression Is Regulated by a SelfGoverning elF5A-PEAK1 Feed-Forward Regulatory Loop. Cancer Res. 2018 Mar 15;78(6):1444-1456. doi: 10.1158/0008-5472.CAN-17-2873.

37. Kim SE, Yoon JY, Jeong WJ, Jeon SH, Park Y, Yoon JB, Park YN, Kim H, Choi KY. H-Ras is degraded by Wnt/beta-catenin signaling via beta-TrCP-mediated polyubiquitylation. J Cell Sci. 2009 Mar 15;122(Pt 6):842-8. doi: 10.1242/jcs.040493.

38. Jeong WJ, Yoon J, Park JC, Lee SH, Lee SH, Kaduwal S, Kim H, Yoon JB, Choi KY. Ras stabilization through aberrant activation of Wnt/ $\beta$-catenin signaling promotes intestinal tumorigenesis. Sci Signal. 2012 Apr 10;5(219):ra30. doi: 10.1126/scisignal.2002242.

39. Spano JP, Fagard R, Soria JC, Rixe O, Khayat D, Milano G. Epidermal growth factor receptor signaling in colorectal cancer: preclinical data and therapeutic perspectives. Ann Oncol. 2005 Feb;16(2):18994. doi:10.1093/annonc/mdi057.

40. Meng M, Zhong K, Jiang T, Liu Z, Kwan HY, Su T. The current understanding on the impact of KRAS on colorectal cancer. Biomed Pharmacother. 2021 Aug;140:111717. doi:10.1016/j.biopha.2021.111717.

41. Chang F, Steelman LS, Lee JT, Shelton JG, Navolanic PM, Blalock WL, Franklin RA, McCubrey JA. Signal transduction mediated by the Ras/Raf/MEK/ERK pathway from cytokine receptors to transcription factors: potential targeting for therapeutic intervention. Leukemia. 2003 Jul;17(7):1263-93. doi: 10.1038/sj.leu.2402945.

42. Brudvik KW, Mise Y, Chung MH, Chun YS, Kopetz SE, Passot G, Conrad C, Maru DM, Aloia TA, Vauthey JN. RAS Mutation Predicts Positive Resection Margins and Narrower Resection Margins in Patients Undergoing Resection of Colorectal Liver Metastases. Ann Surg Oncol. 2016 Aug;23(8):2635-43. doi:10.1245/s10434-016-5187-2.

43. Taveras AG, Remiszewski SW, Doll RJ, Cesarz D, Huang EC, Kirschmeier P, Pramanik BN, Snow ME, Wang YS, del Rosario JD, Vibulbhan B, Bauer BB, Brown JE, Carr D, Catino J, Evans CA, Girijavallabhan V, Heimark L, James L, Liberles S, Nash C, Perkins L, Senior MM, Tsarbopoulos A, Webber SE, et al. Ras oncoprotein inhibitors: the discovery of potent, ras nucleotide exchange inhibitors and the structural determination of a drug-protein complex. Bioorg Med Chem. 1997 Jan;5(1):125-33. doi:10.1016/s0968-0896(96)00202-7. 
44. Porru M, Pompili L, Caruso C, Biroccio A, Leonetti C. Targeting KRAS in metastatic colorectal cancer: current strategies and emerging opportunities. J Exp Clin Cancer Res. 2018 Mar 13;37(1):57. doi: 10.1186/s13046-018-0719-1.

45. Mattox TE, Chen X, Maxuitenko YY, Keeton AB, Piazza GA. Exploiting RAS Nucleotide Cycling as a Strategy for Drugging RAS-Driven Cancers. Int J Mol Sci. 2019 Dec 24;21(1):141. doi: 10.3390/ijms21010141.

46. Deng L, Meng T, Chen L, Wei W, Wang P. The role of ubiquitination in tumorigenesis and targeted drug discovery. Signal Transduct Target Ther. 2020 Feb 29;5(1):11. doi: 10.1038/s41392-020-0107-0.

47. Jin G, Lee SW, Zhang X, Cai Z, Gao Y, Chou PC, Rezaeian AH, Han F, Wang CY, Yao JC, Gong Z, Chan $\mathrm{CH}$, Huang CY, Tsai FJ, Tsai CH, Tu SH, Wu CH, Sarbassov dos D, Ho YS, Lin HK. Skp2-Mediated RagA Ubiquitination Elicits a Negative Feedback to Prevent Amino-Acid-Dependent mTORC1 Hyperactivation by Recruiting GATOR1. Mol Cell. 2015 Jun 18;58(6):989-1000. doi: 10.1016/j.molcel.2015.05.010.

48. Deng L, Jiang C, Chen L, Jin J, Wei J, Zhao L, Chen M, Pan W, Xu Y, Chu H, Wang X, Ge X, Li D, Liao L, Liu M, Li L, Wang P. The ubiquitination of rag A GTPase by RNF152 negatively regulates mTORC1 activation. Mol Cell. 2015 Jun 4;58(5):804-18. doi: 10.1016/j.molcel.2015.03.033.

49. Wang B, Jie Z, Joo D, Ordureau A, Liu P, Gan W, Guo J, Zhang J, North BJ, Dai X, Cheng X, Bian X, Zhang L, Harper JW, Sun SC, Wei W. TRAF2 and OTUD7B govern a ubiquitin-dependent switch that regulates mTORC2 signalling. Nature. 2017 May 18;545(7654):365-369. doi: 10.1038/nature22344.

50. Mao JH, Kim IJ, Wu D, Climent J, Kang HC, DelRosario R, Balmain A. FBXW7 targets mTOR for degradation and cooperates with PTEN in tumor suppression. Science. 2008 Sep 12;321(5895):1499 - 502. doi: 10.1126/science.1162981.

51. Wang X, Trotman LC, Koppie T, Alimonti A, Chen Z, Gao Z, Wang J, Erdjument-Bromage H, Tempst P, Cordon-Cardo C, Pandolfi PP, Jiang X. NEDD4-1 is a proto-oncogenic ubiquitin ligase for PTEN. Cell. 2007 Jan 12;128(1):129 - 39. doi: 10.1016/j.cell.2006.11.039.

52. Yang WL, Wang J, Chan CH, Lee SW, Campos AD, Lamothe B, Hur L, Grabiner BC, Lin X, Darnay BG, Lin HK. The E3 ligase TRAF6 regulates Akt ubiquitination and activation. Science. 2009 Aug 28;325(5944):1134-8. doi: 10.1126/science.1175065.

53. Chan CH, Li CF, Yang WL, Gao Y, Lee SW, Feng Z, Huang HY, Tsai KK, Flores LG, Shao Y, Hazle JD, Yu D, Wei W, Sarbassov D, Hung MC, Nakayama KI, Lin HK. The Skp2-SCF E3 ligase regulates Akt ubiquitination, glycolysis, herceptin sensitivity, and tumorigenesis. Cell. 2012 May 25;149(5):1098 111. doi: 10.1016/j.cell.2012.02.065.

54. Mei Z, Zhang D, Hu B, Wang J, Shen X, Xiao W. FBX032 Targets c-Myc for Proteasomal Degradation and Inhibits c-Myc Activity. J Biol Chem. 2015 Jun 26;290(26):16202-14. doi:

10.1074/jbc.M115.645978.

55. Paul I, Ahmed SF, Bhowmik A, Deb S, Ghosh MK. The ubiquitin ligase CHIP regulates c-Myc stability and transcriptional activity. Oncogene. 2013 Mar 7;32(10):1284-95. doi: 10.1038/onc.2012.144. 
56. Brooks CL, Gu W. p53 ubiquitination: Mdm2 and beyond. Mol Cell. 2006 Feb 3;21(3):307 - 15. doi: 10.1016/j.molcel.2006.01.020.

57. Li M, Chen D, Shiloh A, Luo J, Nikolaev AY, Qin J, Gu W. Deubiquitination of p53 by HAUSP is an important pathway for p53 stabilization. Nature. 2002 Apr 11;416(6881):648 - 53. doi: 10.1038/nature737.

58. Veggiani G, Gerpe MCR, Sidhu SS, Zhang W. Emerging drug development technologies targeting ubiquitination for cancer therapeutics. Pharmacol Ther. 2019 Jul;199:139-54. doi:10.1016/j.pharmthera.2019.03.003.

59. Bernassola F, Karin M, Ciechanover A, Melino G. The HECT family of E3 ubiquitin ligases: multiple players in cancer development. Cancer Cell. 2008 Jul 8;14(1):10-21. doi: 10.1016/j.ccr.2008.06.001.

\section{Tables}

Due to technical limitations, table 1 is only available as a download in the Supplemental Files section.

\section{Figures}


Figure 1

$\mathbf{A}$
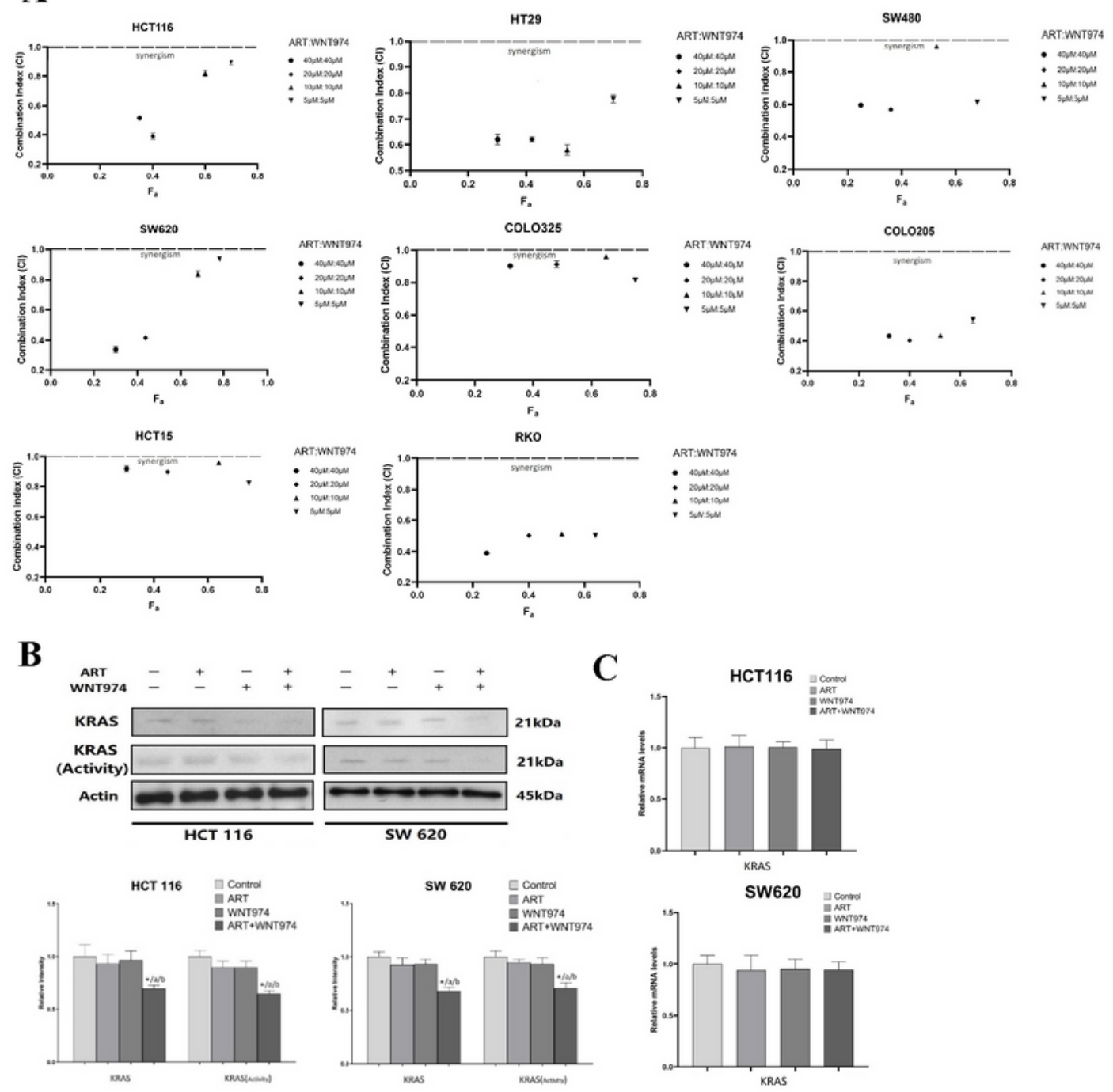

\section{Figure 1}

Combination of WNT974 and artesunate (ART) reduces KRAS protein level and activity in CRC cells. (A) Fraction affected $(\mathrm{Fa})$ versus combination index $(\mathrm{Cl})$ plots were used to determine the extent of synergy for combination treatment in $8 \mathrm{CRC}$ cells, synergistic effects are defined as $\mathrm{Cl}<1$. (B) HCT116 and SW620

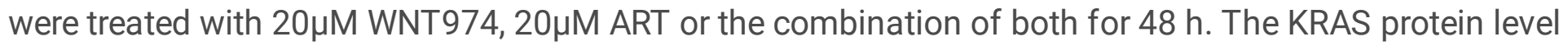
and activity were examined. (C) KRAS mRNA level in HCT116 cells and SW620 cells after treatments. 
Shown is mean $\pm S E, n=3$ individual experiments, ${ }^{*} p<0.05$, compared to control; a $<0.05$, compared to ART; $b<0.05$, compared to WNT974.

Figure 2
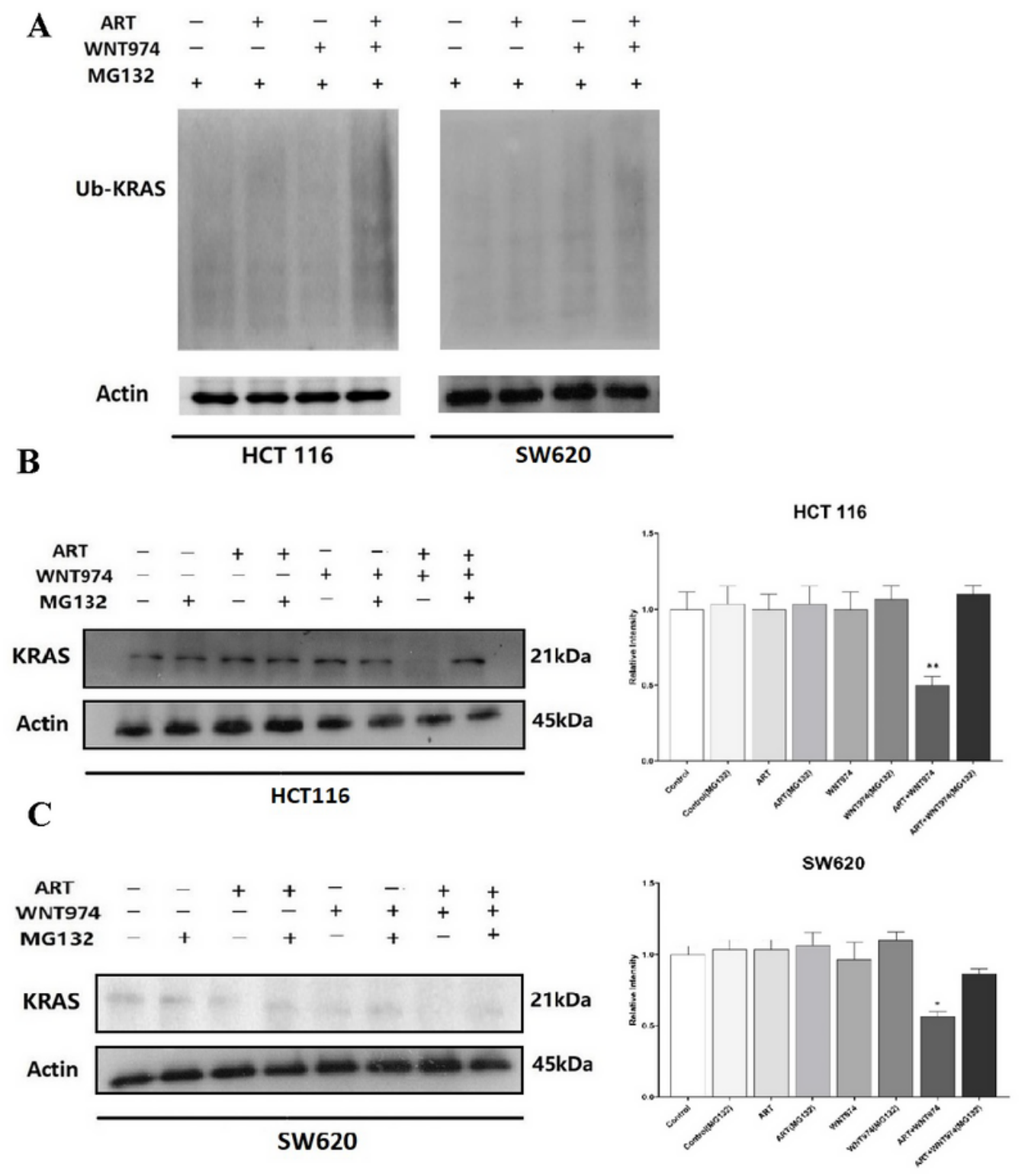

\section{Figure 2}

Combination of WNT974 and ART induces KRAS degradation. (A) HCT116 and SW620 were treated with

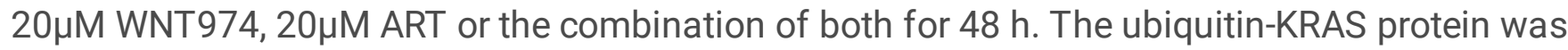
examined by Western blot. The KRAS protein expressions in (B) HCT116 and (C) SW620 cells after the 
treatments in the presence or absence of MG132. Shown is mean $\pm S E, n=3$ individual experiments, ${ }^{*}<$ $0.05,{ }^{*} \mathrm{p}<0.01$ compared to the combination treatment in the presence of MG132.

A

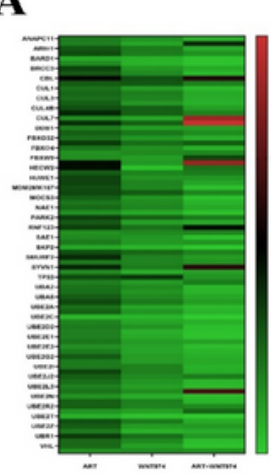

B

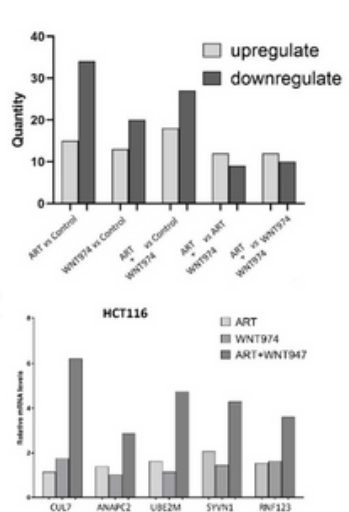

$\mathbf{E}$
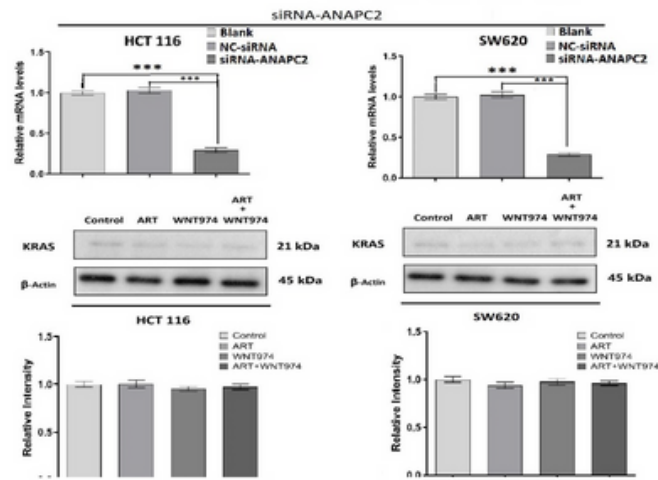

G
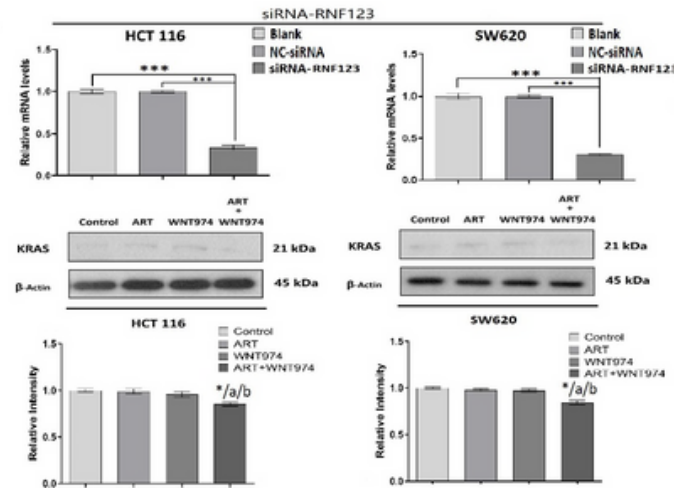

I

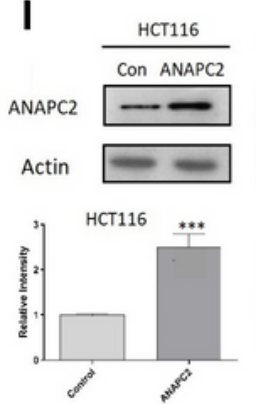

J
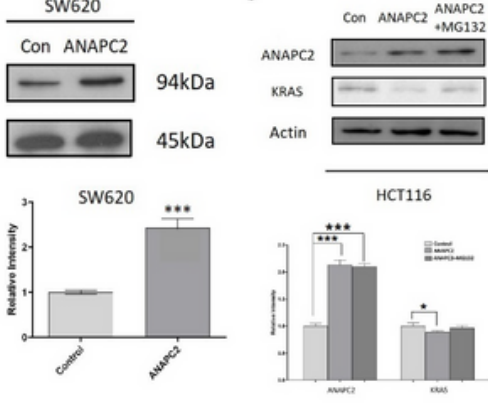

D
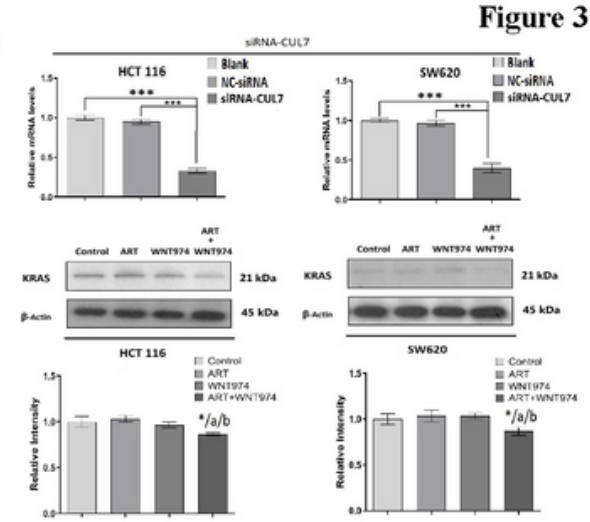

$\mathbf{F}$
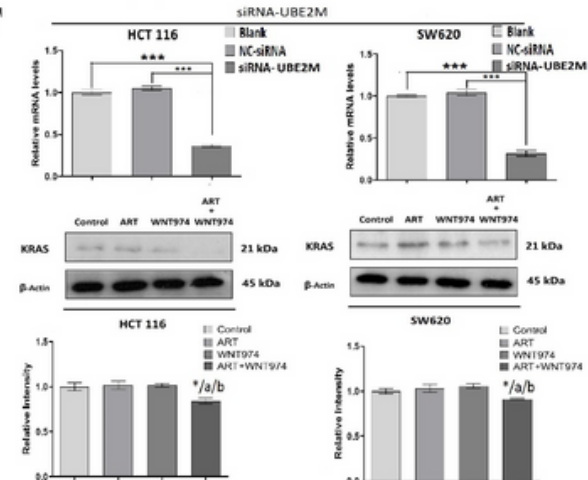

$\mathbf{H}$
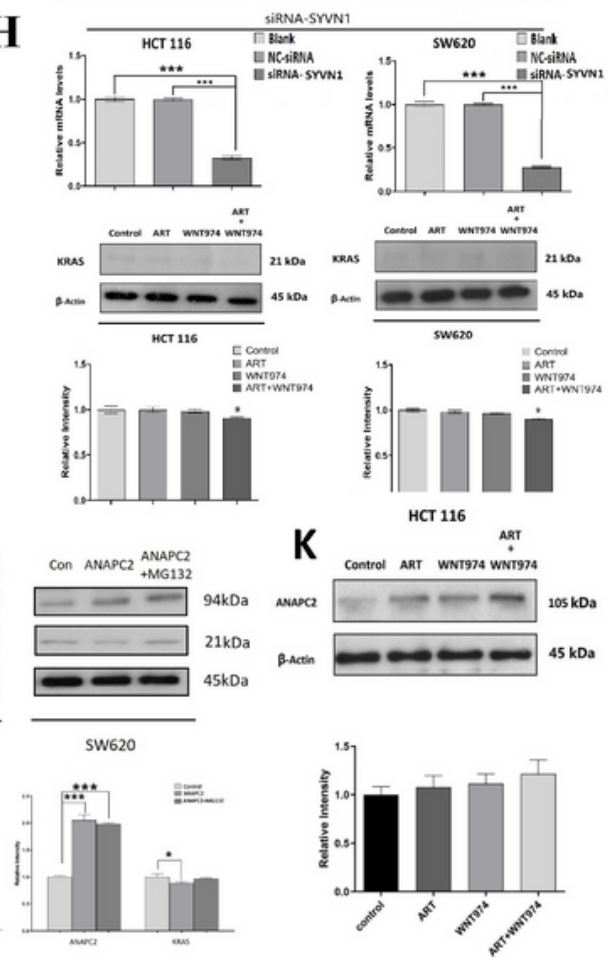

\section{K}

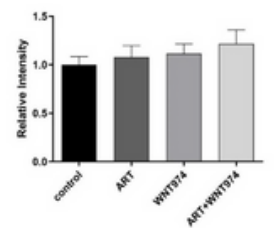

\section{Figure 3}

Combination of WNT974 and ART induces KRAS protein degradation by increasing anaphase promoting

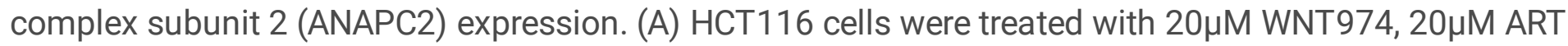
or the combination of both for $48 \mathrm{~h}$. Heat map showing the PCR array results. (B) The numbers of up- or 
down-regulated genes in the PCR array. (C) The mRNA expressions of CUL7 (cullin), ANAPC2 (anaphase promoting complex subunit 2), UBE2M (ubiquitin conjugating enzyme E2M), SYVN1 (synoviolin 1) and RNF123 (RING finger protein123) in the CRC cells after the treatments. KRAS expression in the CRC cells after siRNA-mediated knockdown of (D) CUL7, (E) ANAPC2, (F) UBE2M, (G) RNF123, (H) SYVN1, upper panel showing the expressions of CUL7, ANAPC2, UBE2M, RNF123 and SYNV1 in these cells. (I) Protein expressions of ANAPC2 in ANAPC2-overexpressed CRC cells. (J) Protein expressions of KRAS in ANAPC2overexpressed CRC cells in the presence or absence of MG132. (K) CRC cells were treated with $20 \mu M$

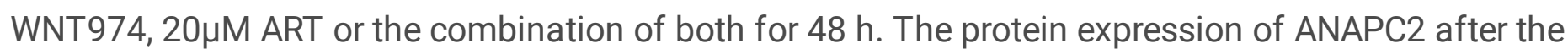

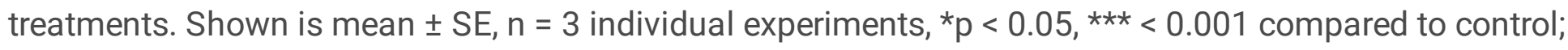
$a<0.05$, compared to ART; $b<0.05$, compared to WNT974. 

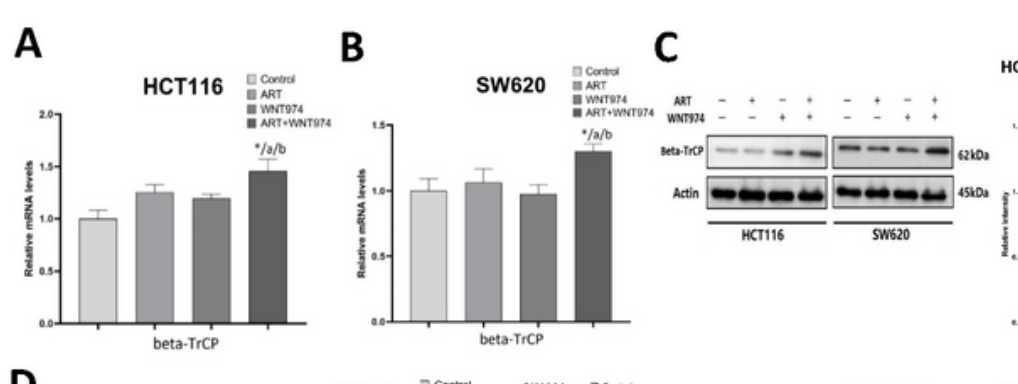

Figure 4

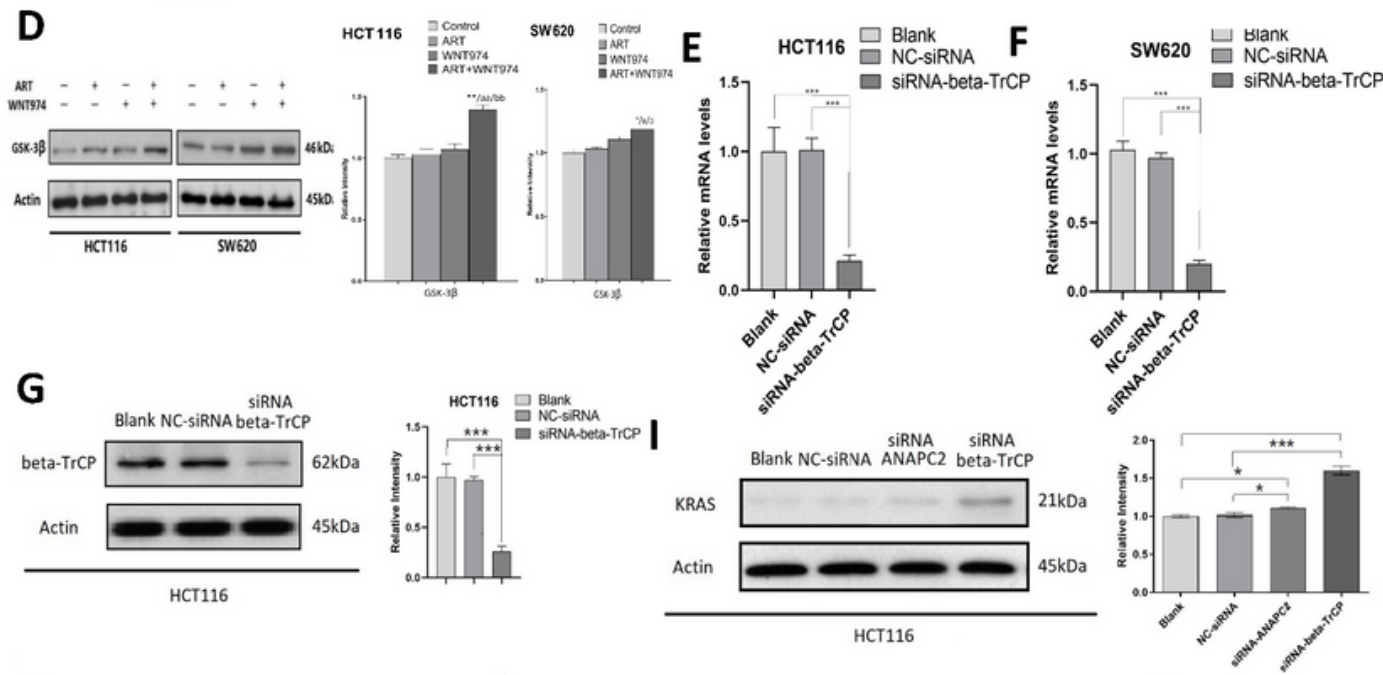

H

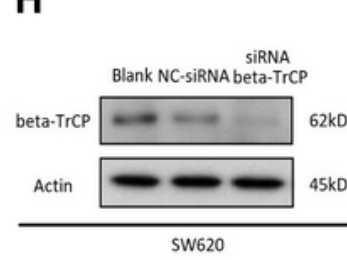

K

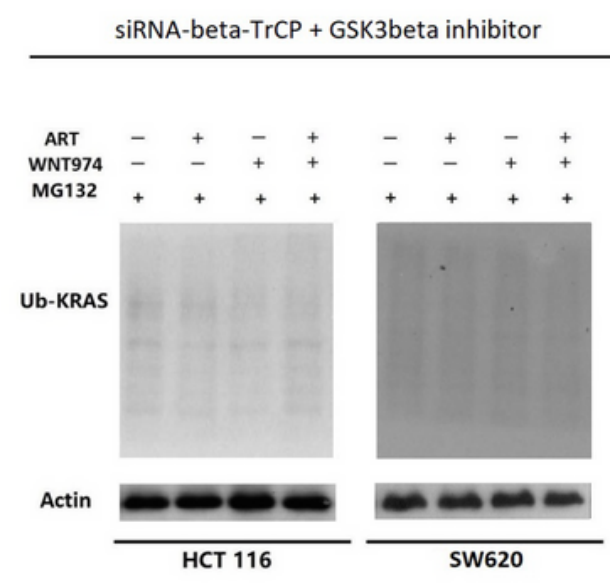

\section{J}
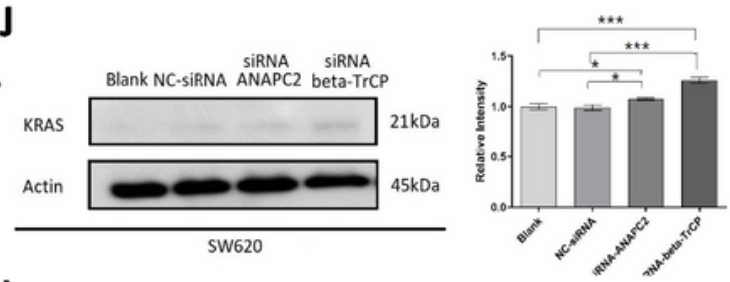

$\mathbf{L}$
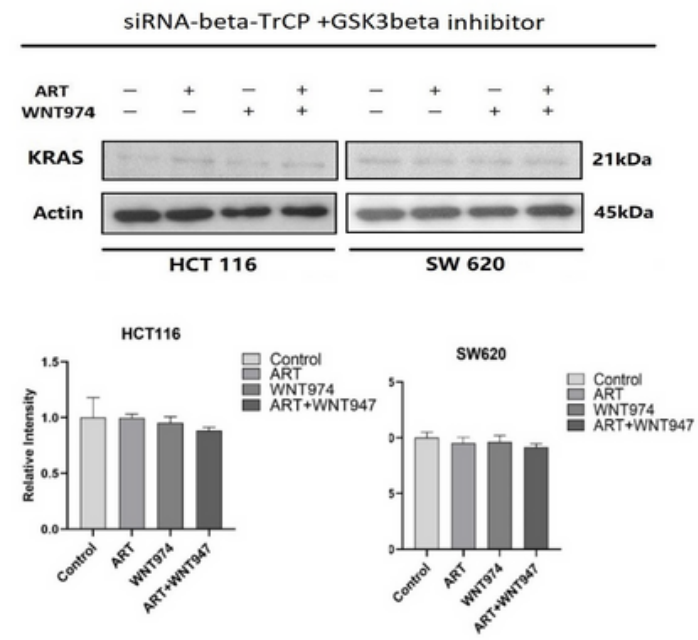

\section{Figure 4}

Combination of WNT974 and ART induces KRAS protein degradation by increasing $\beta$-TrCP and GSK-3 $\beta$

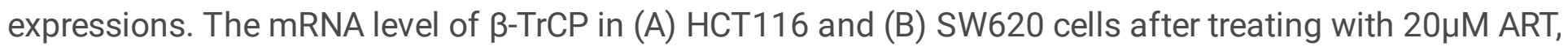
$20 \mu \mathrm{M}$ WNT974 or a combination of both for $48 \mathrm{~h}$. The protein level of (C) $\beta$-TrCP and (D) GSK-3 $\beta$ in the CRC cells after treating with $20 \mu \mathrm{M}$ ART, $20 \mu \mathrm{M}$ WNT974 or a combination of both for $48 \mathrm{~h}$. The (E-F) mRNA expression and $(\mathrm{G}-\mathrm{H})$ protein expression of $\beta$-TrCP after siRNA-mediated knockdown of $\beta$-TrCP in the CRC 
cells. (I-J) Protein expression of KRAS in $\beta$-TrCP-knockdown or ANAPC2-knockdown cells. (K)

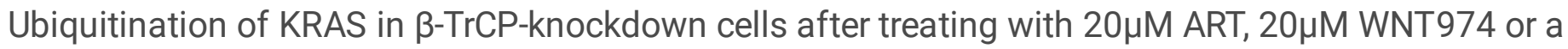
combination of both treatments for $48 \mathrm{~h}$, in the presence of GSK-3 $\beta$ inhibitor. (L) Protein expression of KRAS in the $\beta$-TrCP-knockdown CRC cells after treating with $20 \mu \mathrm{M}$ ART, 20 $\mu \mathrm{M}$ WNT974 or a combination of both for $48 \mathrm{~h}$, in the presence of GSK-3 $\beta$ inhibitor. Shown is mean $\pm \mathrm{SE}, \mathrm{n}=3$ individual experiments, * $\mathrm{p}$ $<0.05$, ${ }^{\star \star} p<0.01,{ }^{* \star *} \mathrm{p}<0.001$ compared to control; $a<0.05$, aa $<0.01$, compared to ART; $b<0.05, \mathrm{bb}<$ 0.01 compared to WNT974.

Figure 5
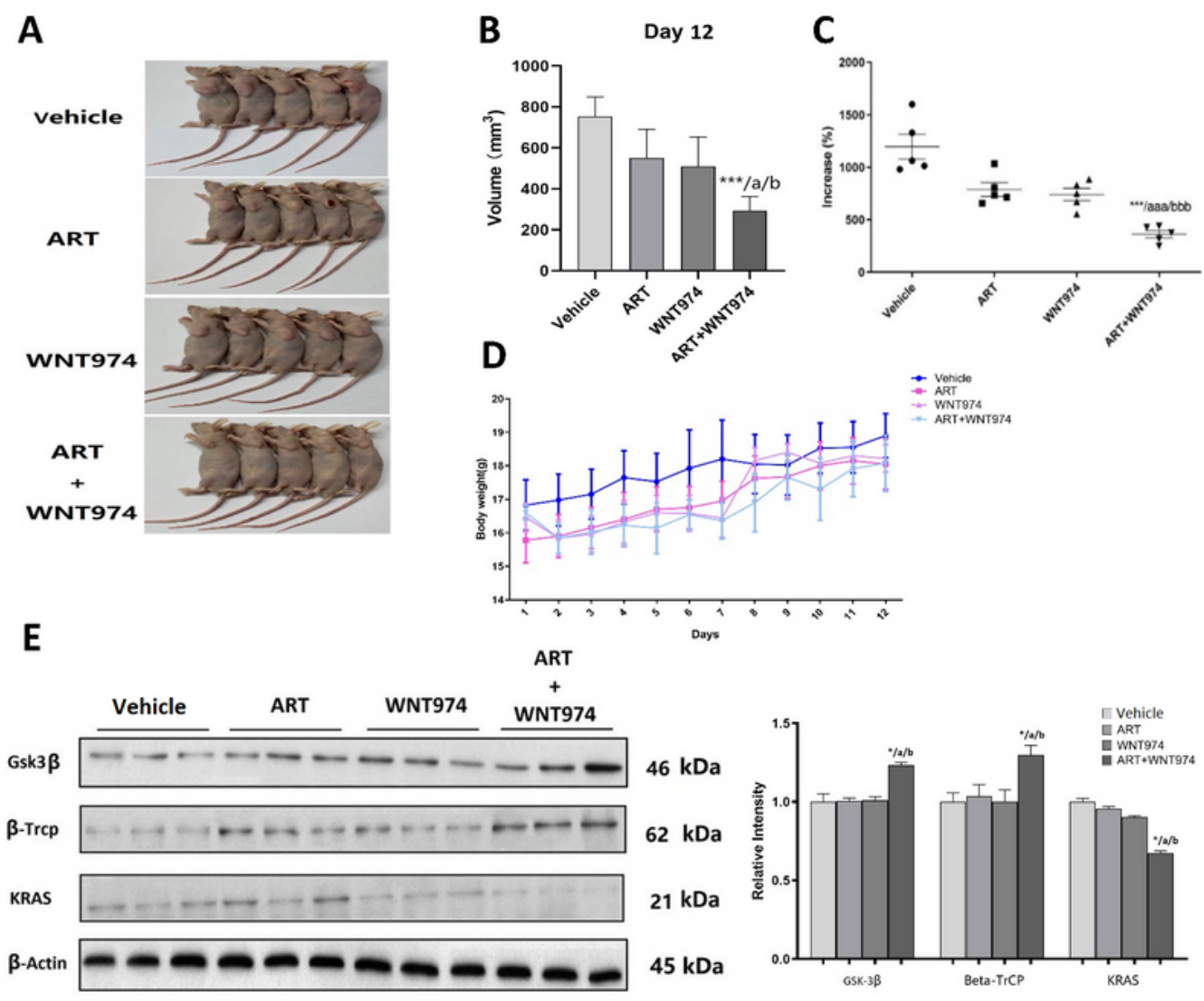

F

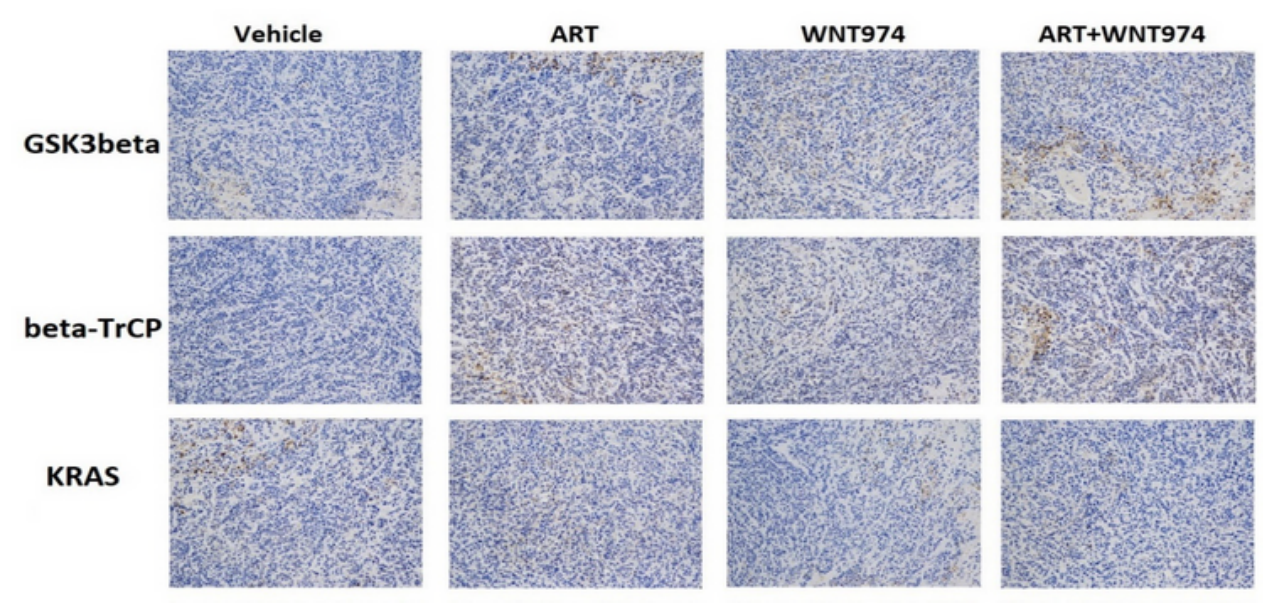


Figure 5

Combination of WNT974 and ART exhibits a potent anti-CRC effect in vivo. (A) The photographs of the CRC-bearing xenograft mouse model in different treatment groups. (B) Tumor volume, (C) \% increase in tumor growth and (D) body weight of the mice. (E) Protein expressions of KRAS, $\beta$-TrCP and GSK-3 $\beta$ in the tumor tissues. (F) IHC analysis of the tumor tissues for KRAS, $\beta$-TrCP and GSK-3 $\beta$ (magnification $x$ 200). Shown is mean $\pm S E, n=5$ mice in each group, ${ }^{\star} p<0.05$, $* * * p<0.001$ compared to control; $a<$ 0.05 , aaa $<0.001$, compared to ART; $b<0.05$, bbb $<0.001$ compared to WNT974.

Figure 6

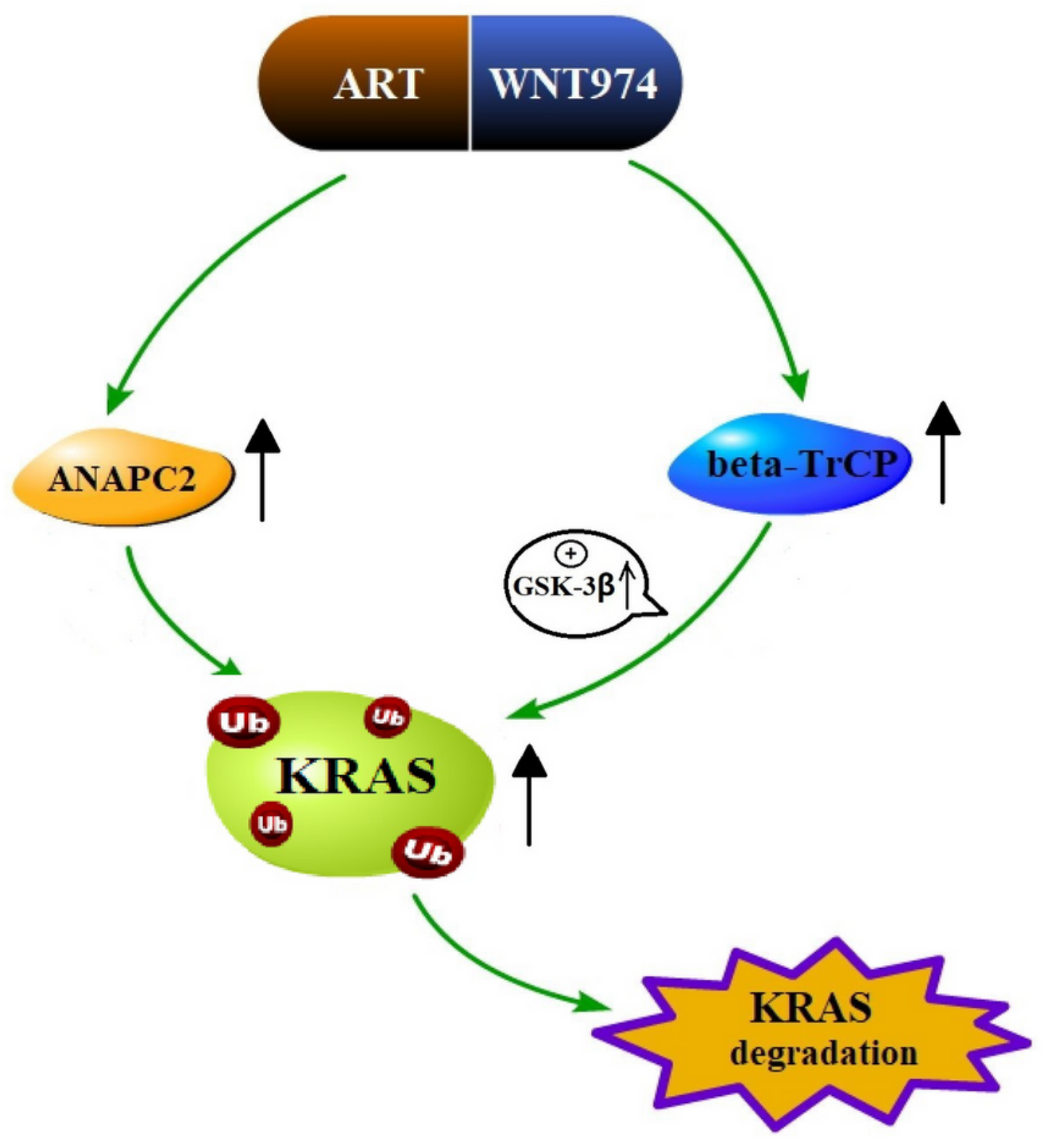


Figure 6

A schematic diagram showing the mechanism of action underlying the synergistic effect of the combination treatment. A schematic diagram showing the combination of WNT974 and ART increases ANAPC2, $\beta$-TrCP and GSK-3 $\beta$ expressions that lead to KRAS protein degradation via the ubiquitination ubiquitin-proteasome pathway.

\section{Supplementary Files}

This is a list of supplementary files associated with this preprint. Click to download.

- Table1.tiff

- SupplementaryFigure1.tiff 